\title{
Smoking, health and ageing
}

Vittorio Nicita-Mauro1, Giorgio Basile1, Giuseppe Maltese', Claudio NicitaMauro $^{1}$, Sebastiano Gangemi ${ }^{2}$ and Calogero Caruso*3

\begin{abstract}
Address: ${ }^{1}$ Chair of Geriatrics and Gerontology, University of Messina, Messina, Italy, ${ }^{2}$ Chair of Allergy and Clinical Immunology, University of Messina, Messina, Italy and ${ }^{3}$ Immunosenescence Unit, University of Palermo, Palermo, Italy

Email: Vittorio Nicita-Mauro - nicitav@unime.it; Giorgio Basile - giorgio.basile@unime.it; Giuseppe Maltese - gmaltese@unime.it; Claudio Nicita-Mauro - claudio.nicitamauro@alice.it; Sebastiano Gangemi -sgangemi@unime.it; Calogero Caruso* - marcoc@unipa.it

* Corresponding author
\end{abstract}

Published: 16 September 2008

Immunity \& Ageing 2008, 5:10 doi:10.1186/1742-4933-5-10
Received: 7 July 2008

Accepted: 16 September 2008

This article is available from: http://www.immunityageing.com/content/5/I/10

(c) 2008 Nicita-Mauro et al; licensee BioMed Central Ltd.

This is an Open Access article distributed under the terms of the Creative Commons Attribution License (http://creativecommons.org/licenses/by/2.0), which permits unrestricted use, distribution, and reproduction in any medium, provided the original work is properly cited.

\begin{abstract}
On March 19, 2008 a Symposium on Pathophysiology of Ageing and Age-Related diseases was held in Palermo, Italy. Here, the lecture of V. Nicita-Mauro on Smoking, health and ageing is summarized. Smoking represents an important ageing accelerator, both directly by triggering an inflammatory responses, and indirectly by favoring the occurrence of several diseases where smoking is a recognized risk factor. Hence, non-smokers can delay the appearance of diseases and of ageing process, so attaining longevity.
\end{abstract}

\section{Background}

On March 19, 2008 a Symposium on Pathophysiology of Ageing and Age-Related diseases was held in Palermo, Italy. Here, the lecture of V. Nicita-Mauro on Smoking, health and ageing is summarized.

Ageing is a very complex biological phenomenon deriving from an interaction between genetic and environmental factors [1]. Among these latter, the smoke of cigarettes represents an important accelerator of the ageing process (Figure 1), both directly through complex mechanisms mediated prevalently by excessive formation of free radicals, and indirectly by favouring the appearance of various pathologies in which smoke is a recognized risk factor [2].

Oxidative stress is a possible mechanism consistent with dangerous effects of smoking since cigarette smoke contains free radicals that activate inflammatory cells with inflammatory mediator production and further oxidative damage $[3,4]$. Smokers have significantly lower erythrocyte CuZn SOD and Se-GSH-Px activities than non-smok- ers [5]. Accordingly, concentrations of serum antioxidant vitamins, such as ascorbic acid and vitamin $\mathrm{E}$, have been reported to be lower in chronic smokers than in nonsmokers [6]. Hence, these findings support the concept that smoking is associated with an increased oxidative stress that may cause and/or accelerate age-related inflammatory diseases [7].

Telomere length represents another possible connection between smoking and ageing. Telomere length shortens with age in all replicating somatic cells, and it has been shown that tobacco smoking enhances telomere shortening in circulating lymphocytes [8], hence worsening the immunosenescence state characteristics of ageing [9].

There is no doubt that smoke is an important risk factor for many diseases, in particular for cardiovascular, neoplastic and respiratory diseases, which are the main causes of death in the industrialized Countries, where smoking habit is also largely diffuse. According to the projections, by the year 2020, smoking will become the main cause of 


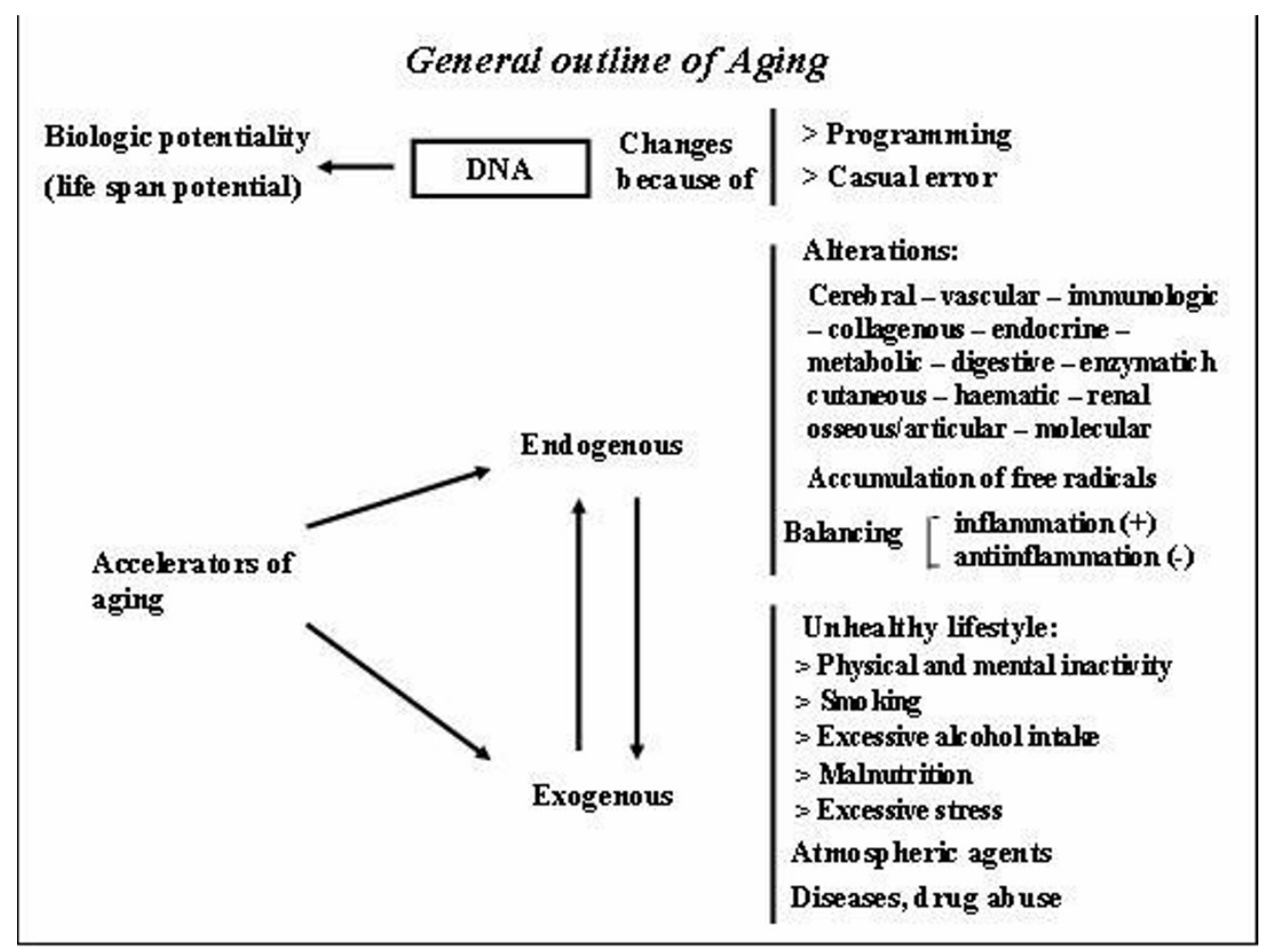

Figure I

General outline of ageing. Smoking represents an important exogenous accelerator of ageing process.

death and disability, with more than 10 million death cases per year [2].

\section{Smoking and age-related diseases}

Smoking plays an important role also in the development of other pathological conditions being particularly frequent in old age, such as dementia, osteoporosis, diabetes, peptic ulcer, gastro-esophageal reflux, erectile dysfunction, senile macular degeneration, nuclear cataract, alterations of hearing and skin. Smoke compromises not only life expectancy, but also the quality of the life, favouring the occurrence of non-autonomy (Figure 2) [2].

The role of smoking in dementia and Alzheimer's disease (AD) has been debated. In the last years, several case-control studies suggested that smoking was associated with decreased risk of dementia $[7,10]$. On the other hand, it has been hypothesized that findings obtained in case-control studies were a consequence of survival bias rather than a true protective effect of smoking [11]. However, the mechanisms by which smoking would prevent the risk of $\mathrm{AD}$ should be related to the positive nicotinic effects of smoking on cognitive functioning $[7,12]$. On the other hand, the increased frequency of cardiovascular and cerebrovascular illnesses among smokers is likely to increase the risk of $\mathrm{AD}$ in later life $[13,14]$. Thus, the association between smoking and risk of dementia, including AD, is debated. However, the results of a recent meta-analysis of prospective studies clearly showed that, when compared

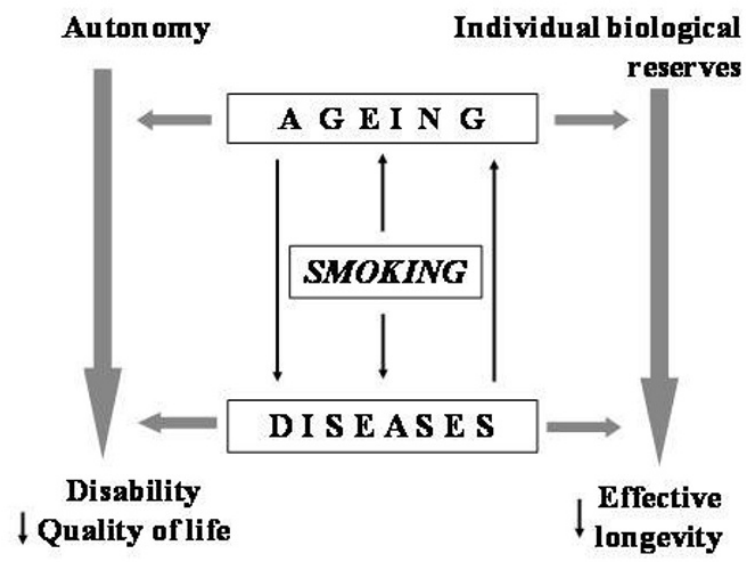

Figure 2

Cigarette smoking is an important risk factor for many diseases and an accelerator of ageing, it compromises not only life expectancy but also the quality of life. 
with people who have never smoked, current smokers have an increased risk of dementia and cognitive decline ranging from 40 percent to 80 percent, depending on the outcome examined [10].

As regards the relationships between smoking and cardiovascular system, several studies have shown that smokers have higher average systolic blood pressure values, compared to non-smokers, further, smokers do not have the physiological nocturnal decrease of the blood pressure levels [2]. However, the after-smoking increase of the arterial blood pressure can be abolished by a preventive application of the calcium-antagonist nifedipin [15]. The smoke is able to cause tissue oxidative damage at various levels, and contributes significantly to the appearance of endothelial dysfunctions, and to the alterations which induce the arteriosclerotic process. It is known that in smoker subjects the oxidative stress derives from excessive increase of free radicals and reduction of the antioxidant mechanisms (enzymatic and non-enzymatic type). It has been shown that the alteration of endothelial vasoregulatory activity is independent from the number of smoked cigarettes, as this activity was similar in subjects who smoked one package of cigarettes per week or per day (or less) [2].

A lot of epidemiologic study support the role of smoke in acute coronary syndrome (ACS) and myocardial infarction (MI). It is noteworthy that the MI incidence of in Britain has fallen markedly in recent years. The British Regional Heart Study examined changes in cardiovascular risk factors and MI incidence over 25 years from 1978 in a cohort of 7735 men. The hazard of MI decreased of a $62 \%$ decline over the 25 years. Forty-six percent of this decrease in MI hazard could be explained by a combination of changes in the major risk factors over this time: a fall in the number of cigarette smokers was the most powerful of all [16]. Furthermore, in a follow up of 54783 women and men from the prospective Danish Diet, Cancer and Health study who were 50 to 64 years at baseline and free of coronary artery disease, during a median of 7.7 years, 1127 incident cases of occurred. Obesity conferred an elevated risk of ACS in both healthy and less healthy subgroups of lifestyle behaviors: however, the authors found that obese individuals had a considerable lower risk if they were nonsmokers [17].

Non-smokers have a much higher life expectancy than smokers[18], and the suspension of smoking is accompanied, even in the elderly, by an increase in the survival time due to the reduction of smoke-induced biological damage. Therefore, cigarette smoking is opposing the longevity, particularly the extreme one, as it is confirmed by the observations obtained on centenarians [2]. Tobacco smoking is associated with a compromised health status and impaired autonomy also in the centenarians.

Modifiable healthy behaviours during early elderly years, including smoking abstinence, weight management, blood pressure control, and regular exercise, are associated not only with enhanced life span in men but also with good health and function during old age [19].

Considering the demonstrated beneficial effects of suspension of smoking, all practitioners and geriatricians in particular, should promote the abstinence from smoking as a behavioural norm for a correct life style.

Therefore, it is our duty to notify non smokers to keep non-smoking, and to the smokers to abandon smoking, evidencing the risks related to smoking, and the limitations to health deriving from this habit. On the other hand, we have to illustrate also the better performance that non-smokers may achieve. The invitation by the practitioner to stop smoking may be effective, but often this possibility is not utilized properly, in particular as far as elderly subjects is concerned: indeed these subjects often were never been told to leave smoking [20].

\section{Conclusions: Stopping Smoking}

The first requirement of stopping smoking is certainly the motivation of the smoker himself to do this, since without this motivation any attempt is vane. Today, numerous strategies exist, either of pharmacological or non-pharmacological type, which are advantageous also for the elderly. The most effective smoking cessation programs involve a combination of pharmacotherapy and behavioural and/or cognitive counselling to improve abstinence rates.

Approved pharmacological treatments include nicotine replacement therapies, bupropion, a non nicotine option, antidepressants, drugs targeting cannabinoid receptors and newer pharmacological approaches including the selective nicotinic partial agonists [21-26].

Nicotine can be applied in various ways, but the best is certainly the transdermic method through the application of patches. The efficacy of the nicotine patches has widely been documented in a series of studies, together with the contraindications, the side effects, the pharmacological interactions, even for the elderly subjects [20,21]. Another method is the use of an antidepressant, called bupropione, which has demonstrated good efficacy as both a monotherapy, and in association with nicotine patches [22].

Varenicline, an alpha4beta2 nicotinic acetylcholine receptor partial agonist, is the most recent agent approved for 
smoking cessation. This drug works by reducing the strength of the smoker's urge to smoke and by relieving withdrawal symptoms. Varenicline mimics the effect of nicotine and hence reduces craving when smokers stop. Furthermore, varenicline blocks nicotine receptors and in this manner, provokes a weaker response to nicotine if smokers use tobacco products while taking the drug. Recent evidence suggests that the nicotin-receptor partial agonist varenicline is at least as effective as nicotine replacement therapy and antidepressants [23-26].

\section{Competing interests}

The authors declare that they have no competing interests.

\section{Authors' contributions}

All authors contributed equally to the paper and read and approved the final manuscript.

\section{Acknowledgements}

The meeting organizer Prof. C. Caruso is deeply indebted to the speakers and chairpersons of the meeting (Frans Claas, Biagio Agostaro, Marco Racchi, Giovanni Scapagnini, Daniela Mari, Vittorio Nicita-Mauro, Mario Barbagallo, Giuseppina Candore, Giuseppina Colonna-Romano, Domenico Lio) who contributed to the scientific success of the symposium. In addition, the same day of the meeting the defence of $\mathrm{PhD}$ thesis of students belonging to the Pathobiology PhD course directed by CC was held. Prof. Caruso is proud of the hard and challenging work of his students which motivation and enthusiasm, with the management of Drs. Giuseppina Candore, Giuseppina Colonna-Romano and Prof. Domenico Lio have permitted to the whole Immunosenescence Unit to grow in the field of immunosenescence.

\section{References}

I. Vasto S, Candore G, Balistreri CR, Caruso M, Colonna-Romano G, Grimaldi MP, Listi F, Nuzzo D, Lio D, Caruso C: Inflammatory networks in ageing, age-related diseases and longevity. Mech Ageing Dev 2007, I 28:83-91.

2. Nicita-Mauro V, Lo Balbo C, Mento A, Nicita-Mauro C, Maltese G, Basile G: Smoking, aging and the centenarians. Exp Gerontol 2008, 43:95-101.

3. Crowley Weber CL, Dvorakova K, Crowley C, Bernstein H, Bernstein C, Garewal H, Payne CM: Nicotine increases oxidative stress, activates NF-kappaB and GRP78, induces apoptosis and sensitizes cells to genotoxic/xenobiotic stresses by a multiple stress inducer, deoxycholate: relevance to colon carcinogenesis. Chem Biol Interact 2003, I 45:53-66.

4. Polidori MC, Mecocci P, Stahl W, Sies H: Cigarette smoking cessation increases plasma levels of several antioxidant micronutrients and improves resistance towards oxidative challenge. BrJ Nutr 2003, 90: I47-I50.

5. Ueta E, Tadokoro Y, Yamamoto T, Yamane C, Suzuki E, Nanba E, Otsuka $Y$, Kurata $T$ : The effect of cigarette smoke exposure and ascorbic Acid intake on gene expression of antioxidant enzymes and other related enzymes in the livers and lungs of shionogi rats with osteogenic disorders. Toxicol Sci 2003, 73:339-347.

6. Antoniades $C$, Tousoulis D, Tentolouris $C$, Tsioufis C, Toutouza M, Toutouzas $P$, Stefanadis $C$ : Effects of antioxidant vitamins $\mathbf{C}$ and $E$ on endothelial function and thrombosis/fibrinolysis system in smokers. Thromb Haemost 2003, 89:990-995.

7. Juan DDHD, Li J, Wang JYJ, Gao C, Chen M: A 2-year follow-up study of cigarette smoking and risk of dementia. Eur J Neurol 2004, I I:277-282.

8. Moria M, Busquets X, Pons J, Sauleda J, MacNee W, Agusti AGN: Telomere Shortening in smokers with and without COPD. Eur Respir J 2006, 27:525-528.
9. Candore G, Balistreri CR, Colonna-Romano G, Grimaldi MP, Lio D, Listi' F, Scola L, Vasto S, Caruso C: Immunosenescence and antiimmunosenescence therapies: the case of probiotics. Rejuvenation Res 2008, I I:425-32.

10. Anstey KJ, von Sanden C, Salim A, O'Kearney R: Smoking as a Risk Factor for Dementia and Cognitive Decline: A Meta-Analysis of Prospective Studies. Am J Epidemiol 2007, I 66:367-378.

II. Riggs JE: Smoking and Alzheimer 2000's disease: protective effect or differential survival bias? Lancet 1993, 342:793-794.

12. Elrod K, Buccafusco JJ, Jackson WJ: Nicotine enhances delayed matching-to-sample performance by primates. Life Sci I988, 43:277-87.

13. Skoog L: Status of risk factors for vascular dementia. Neuroepidemiology 1998, 1 7:2-9.

14. Esiri M, Nagy Z, Smith MZ, Barnetson L, Smith AD: Cerebrovascular disease and threshold for dementia in the early stages of Alzheimer's disease. Lancet 1999, 354:919-920.

15. Nicita-Mauro V: Smoking, calcium, calcium antagonists, and aging. Exp Gerontol 1990, 25:393-399.

16. Hardoon SL, Whincup PH, Lennon LT, Wannamethee SG, Capewell S, Morris RW: How Much of the Recent Decline in the Incidence of Myocardial Infarction in British Men Can Be Explained by Changes in Cardiovascular Risk Factors?: Evidence From a Prospective Population-Based Study. Circulation 2008, I I 7:598-604.

17. Jensen MK, Chiuve SE, Rimm EB, Dethlefsen C, Tjønneland A, Joensen AM, Overvad K: Obesity, Behavioral Lifestyle Factors, and Risk of Acute Coronary Events. Circulation 2008, I I 7:3062-3069.

18. Doll R, Peto R, Boreham J, Sutherland I: Mortality in relation to smoking: $\mathbf{5 0}$ years' observations on male British doctors. $\mathrm{Br}$ Med J 2004, 328:1519-15.

19. Yates LB, Djousse L, Kurth T, Buring JE, Gaziano JM: Exceptional Longevity in men. Arch Intern Med 2008, I 68:284-290.

20. Bratzler DW, Oehlert WH, Austelle A: Smoking in the elderly. It's never too late to quit. J Okla State Med Assoc 2002, 95:185-191.

21. Gourlay SG, Benowitz NL: The benefits of stopping smoking and the role of nicotine replacement therapy in older patients. Drugs Aging 1996, 9:8-23.

22. Jorenby DE, Leischow SJ, Nides MA, Rennard SI, Johnston JA, Hughes AR, Smith SS, Muramoto ML, Daughton DM, Doan K, Fiore MC, Baker TB: A controlled trial of sustainedrelease bupropion, a nicotine patch, or both for smoking cessation. $N$ Engl J Med 1999, 340:685-69|.

23. Tonstad S, Tønnesen P, Hajek P, William KE, Billing CB, Reeves KR: Varenicline Phase 3 Study Group. Effect of maintenance therapy with varenicline on smoking cessation: a randomized controlled trial. JAMA 2006, 296:64-7I.

24. Jorenby DE, Hays JT, Rigotti NA, Azoulay S, Watsky EJ, William KE, Billing CB, Gong J, Reeves KR: Varenicline Phase 3 Study Group. Efficacy of varenicline, an alpha4beta2 nicotinic acetylcholine receptor partial agonist, vs placebo or sustained-release bupropion for smoking cessation: a randomized controlled trial. JAMA 2006, 296:56-63.

25. Taylor Hays J, Ebbert JO, Sood A: Efficacy and safety of varenicline for smoking cessation. AJM 2008, I 2 I :S32-S42.

26. Nides $M$ : Update on pharmacological options for smoking cessation treatment. AJM 2008, I 21 :S20-S3I.

Publish with Bio Med Central and every scientist can read your work free of charge

"BioMed Central will be the most significant development for disseminating the results of biomedical research in our lifetime. "

Sir Paul Nurse, Cancer Research UK

Your research papers will be:

- available free of charge to the entire biomedical community

- peer reviewed and published immediately upon acceptance

- cited in PubMed and archived on PubMed Central

- yours - you keep the copyright 